Abner L. Chan, MD'

Ryner Jose D. Carrillo, MD, MSc ${ }^{1,2}$

Kimberly C. Ong, $\mathrm{MD}^{3}$

'Department of Otorhinolaryngology

College of Medicine - Philippine General Hospital

University of the Philippines Manila

\section{Department of Anatomy}

College of Medicine

University of the Philippines Manila

${ }^{3}$ Department of Otorhinolaryngology

Philippine General Hospital

University of the Philippines Manila
Correspondence: Dr. Abner L. Chan Department of Otorhinolaryngology Philippine General Hospital Ward 10 University of the Philippines Manila

Taft Avenue, Ermita, Manila 1000 Philippines

Phone: (632) 5548400 local 2152

Email: orl.up.pgh@gmail.com

The authors declare that this represents original material, that the manuscript has been read and approved by all the authors, that the requirements for authorship have been met by each author, and that each author believes that the manuscript represents honest work.

Disclosures: The authors signed disclosures that there are no financial or other (including personal) relationships, intellectual passion, political or religious beliefs, and institutional affiliations that might lead to a conflict of interest.

\title{
Simulation Platform for Myringotomy with Ventilation Tube Insertion in Adult Ears
}

\begin{abstract}
Objective: To develop a ventilation tube insertion simulator for training and evaluation of otorhinolaryngology residents in myringotomy with ventilating tube insertion.

\section{Methods:}

$\begin{array}{ll}\text { Design: } & \text { Cross Sectional Study } \\ \text { Setting: } & \text { Tertiary National University Hospital } \\ \text { Participants: } & \text { Otologists and otorhinolaryngology resident trainees }\end{array}$

A simulation tool for myringotomy with ventilation tube insertion was fabricated using silicone sealant, aluminum tube, rubber ball, plaster of Paris and plastic sheet and pretested by our expert panel. Residents were then evaluated using an objective structured clinical examination (OSCE) checklist while performing the procedure using the same model. Three trials were given and OSCE scores were obtained for each resident.
\end{abstract}

Results: The pinna, ear canal, tympanic membrane, malleus handle were deemed realistic by the expert panel. Residents performed the procedure at an average of 87 seconds. Average OSCE score for all residents was 17.17, with senior residents having a higher average score (18.3) than junior residents (16.6). However, this was not statistically significant (2 tailed t-value, significance level $0.05=-1.27, p=.227$ ). The most common cause of trial failure was dropping of the tube in the middle ear while the most common error made was using more than 2 attempts at performing the incision.

Conclusion: This simulation platform may be a valuable tool to use in educating and developing skills and proper technique of myringotomy with ventilation tube insertion. It is reproducible, affordable, realistic, sturdy and versatile in its applications. Residents who show adequate dexterity and consistency during simulation may eventually be allowed to perform the procedure on patients and provide feedback regarding the usefulness of the simulation.

Keywords: otitis media with effusion, middle ear ventilation, tympanic membrane, models, educational, simulation training, patient simulation

Myringotomy with ventilation tube insertion (MVTI) is a basic otolaryngologic procedure and among the most frequently performed otologic surgical procedures in children. Competence and confidence in performing this surgical procedure are mandatory for any ear, nose, throat (ENT) surgery resident-in-training. Simulations have long been used as a method for teaching trainees to develop various practical skills. 
Numerous simulation platforms for MVTI have already been made internationally and locally using various materials with different levels of replicability, validity and cost. ${ }^{1-3}$ There have also been a number of innovations to make this procedure simpler and less traumatic for the patient such as the use of a self-made tube with a corresponding applicator ${ }^{4,5}$ performing the procedure endoscopically ${ }^{6}$ and using an optical myringotomy knife. ${ }^{7}$ However, there is a need to evaluate and improve a trainee's dexterity in performing this basic procedure beginning with adult then in pediatric ears. Practicing on expensive systems and/or fresh cadavers is not practical and not readily accessible to residents while more affordable models are less likely to simulate accurate anatomy. In actual surgery, errors like dropping a ventilation tube into the middle ear may result in complicated sequelae. Therefore, there is need for a simulation platform successively approximating the narrow working space of the ear canal.

Using an adult ear model as an initial starting point for beginners, the objective of this study is to develop a simulation model that can be used to teach, evaluate and improve the MVTI skills of otorhinolaryngology residents.

\section{METHODS}

This study was approved by the University of the Philippines Manila Research Ethics Board.

\section{Development of a Simulation Model}

A premade auricular template for the right ear made from cast stone available at the prosthesis unit of the Department of Otorhinolaryngology, Philippine General Hospital, University of the Philippines Manila was used as our model. (Figure 1) A negative impression was developed using Kromopan ${ }^{\circledR}$ alginate cast (Lascod, Italy). Then, Prosil ${ }^{\text {TM }}$ multipurpose silicone sealant (GE Silicone, USA) was used to fill the alginate cast to develop the pinna and simulate the cartilaginous portion (medial portion of the alginate model) of the external auditory canal. Marie's Acrylic Colour Paint \#684, \#215, and \#104 (Shanghai SIIC Marie Painting Materials Co., Ltd., China) were mixed to obtain a natural skin color.

An aluminum metal tube with a length of $2.5 \mathrm{~cm}$ (approximate length of the external auditory canal) and a diameter of $1 \mathrm{~cm}$ (approximate diameter of the tympanic membrane) was used to simulate the bony portion of the external auditory canal. The distal end was cut at a 45-degree angle. (Figure 2A) The longer side of the tube was positioned anteriorly. A small flat aluminum rod was placed at the 1 o'clock position and bent at the $6 \mathrm{~mm}$ mark with the angle adjusted to simulate the malleus handle. (Figure 2B\&C) This metal rod was soldered to the tube. The rod-free, non-angulated end of the metal tube was attached to the silicone ear model (Figure 3A\&B) obtaining a final EAC length of $2.8 \mathrm{~cm}$. Commercially-available white polyethylene sheets (plastic) were used to create an artificial tympanic membrane, which could be easily replaced in under a minute. (Figure 3 C) A florist plastic water tube with cap (Figure 3D) filled with water was then attached to the tympanic end of the aluminum tube to simulate the middle ear with effusion.

A mount was made using a rubber ball filled with plaster of Paris. (Figure 4A) Using a ball allowed us to adjust the position of the model. (Figure 4B) Endotracheal tubes that were bent to form a circular structure were used to keep the mount in place. (Figure 4C)

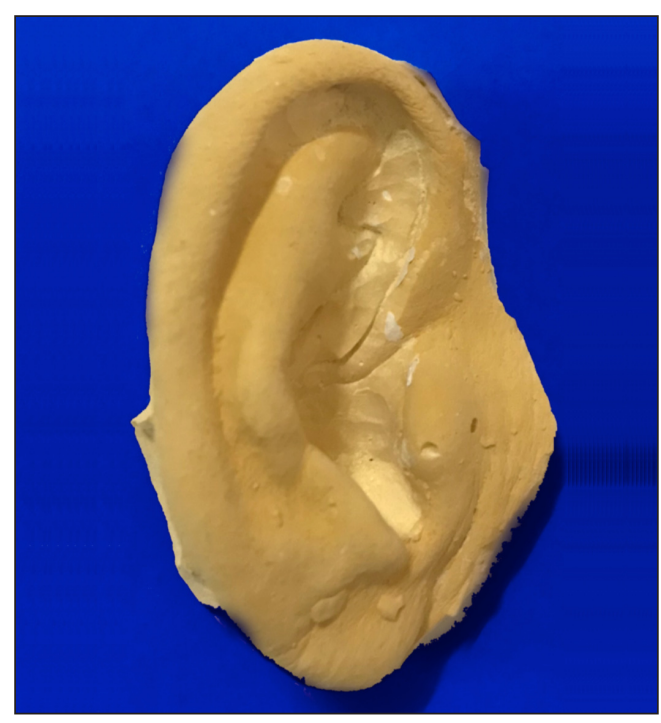

Figure 1. Right auricular template made from cast stone

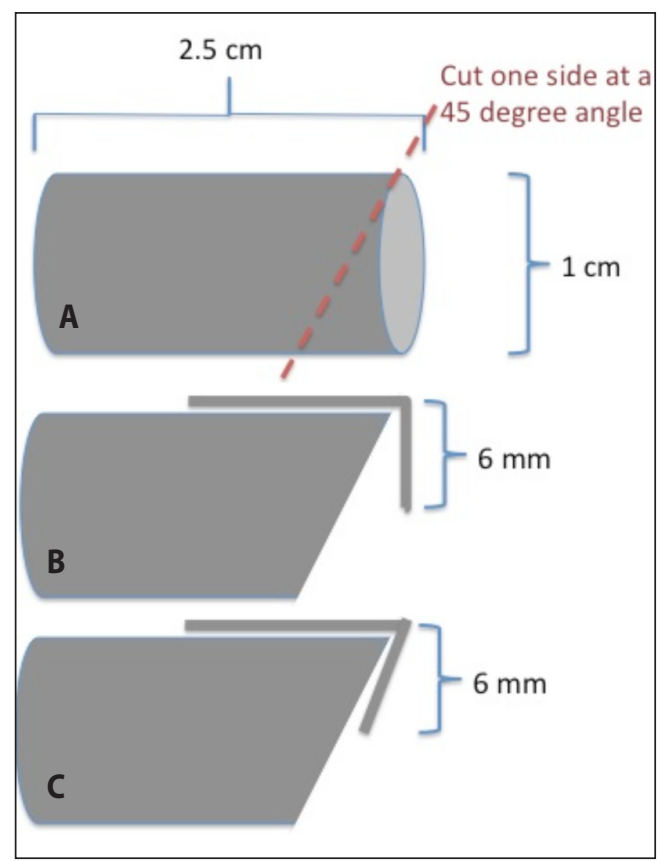

Figure 2. A. metal tube dimensions, B. dimensions of the flat metal rod; and $\mathbf{C}$. attachment to the metal tube. 


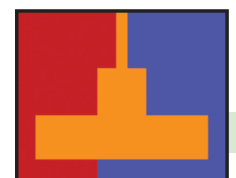

\section{ORIGINAL ARTICLES}

Philipine Journal Of Otolaryngology-Head And Neck Surgery

Vol. 33 No. 2 July - DeCEMBER 2018

PJOHES
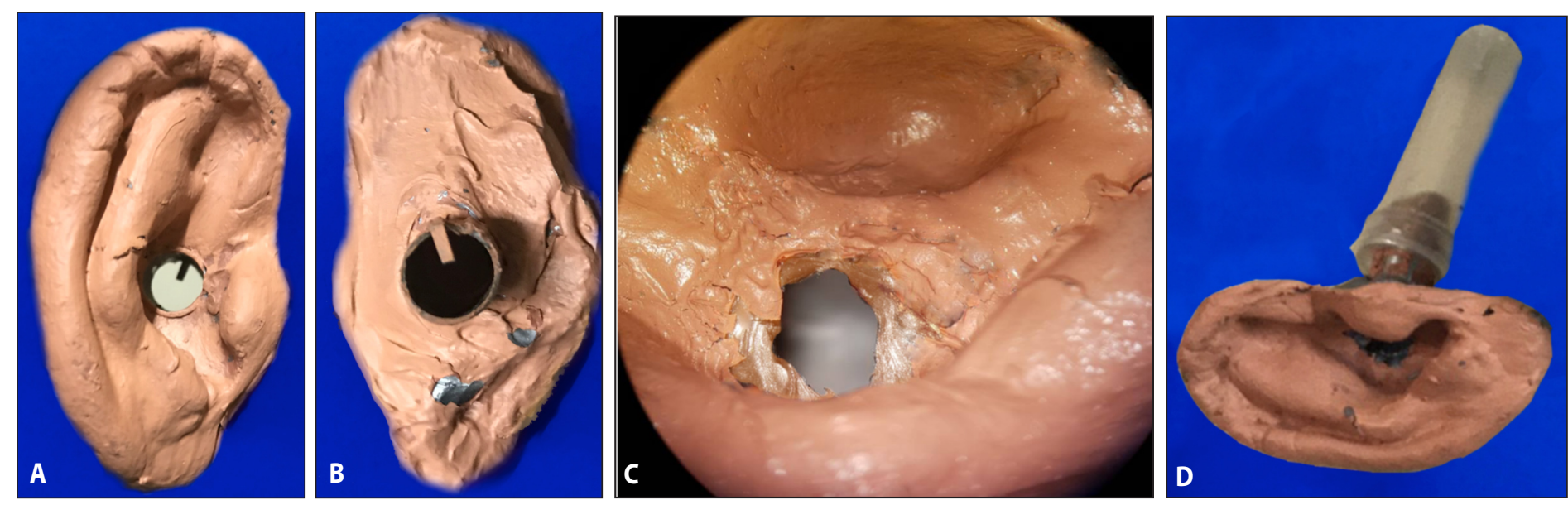

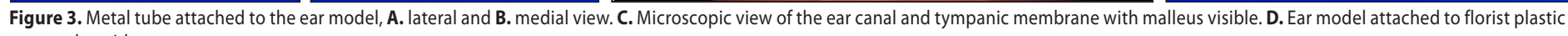
water tube with cap.
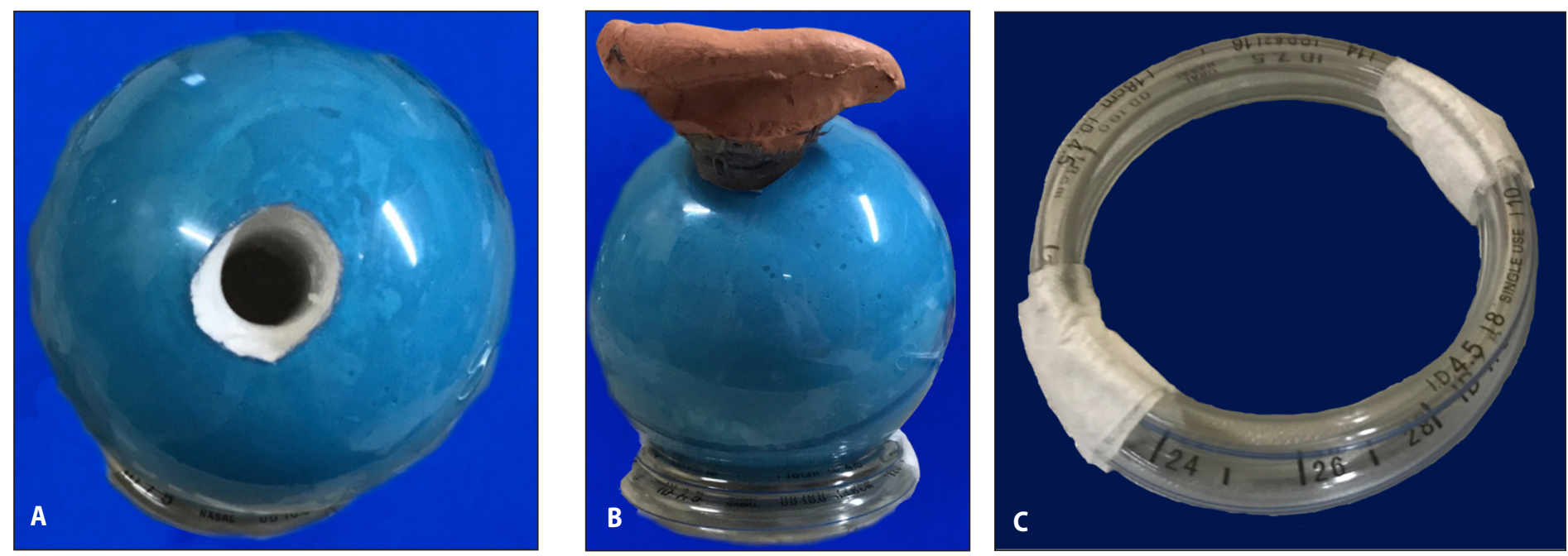

Figure 4. A. Rubber ball filled with plaster of Paris, B. with ear model mounted. C. Mount cradled by endotracheal tubes that formed a circle.

\section{Qualitative Validation of Simulation Model by Experts}

Three otorhinolaryngology (ORL) consultants with at least 10 years of active surgical practice were asked to pretest the model 3 times. Each trial was timed. The consultants evaluated the simulation experience as it compares to actual patient encounter. (Table 1)

\section{Qualitative Validation of Simulation Model by Trainees}

With informed consent, $15 \mathrm{ORL}$ residents watched two short videos ${ }^{8,9}$ on MVTI. The videos illustrated standard techniques for myringotomy using a myringotomy knife and tube insertion using microforceps. Although the second video ${ }^{9}$ involved placing the VT adjacent to the incision and nudging it into the myringotomy, the residents were instructed to place the VT directly into the myringotomy incision with forceps as demonstrated in the first video. ${ }^{8}$ Each resident performed 3 timed trials of the procedure using the simulation model.

All participants (consultants and residents) used the same equipment and same set of instruments including a Boucheron endaural speculum (\#371519, ReSource Surgical Equipment, USA), Shepard grommets (VT-0204, Santa Barbara Medco, Inc., USA), a folding myringotomy knife (Ed Welch Antiques, USA), Rosen suction tip gauge 15 (FDP Medical Instruments USA), and micro-aural crocodile forceps (\#1425, Jull Surg, India). (Figure 5, 6) Participants were required to perform three procedures: (1) myringotomy, (2) suctioning of middle ear fluid and (3) placement of ventilation tube. They did the procedure using a microscope (Karl Kaps SOM82, Germany) with the model positioned as if the patient was supine. They were evaluated on speed and number of errors committed.

A digital stopwatch was used to record the time. Measurement of time began when the knife was inserted past the speculum and ended when the tip of the crocodile ear forceps was withdrawn after placement of the tube. One investigator observed all participants through a second lens, recording times and errors. 
ORIGINAL ARTICLES

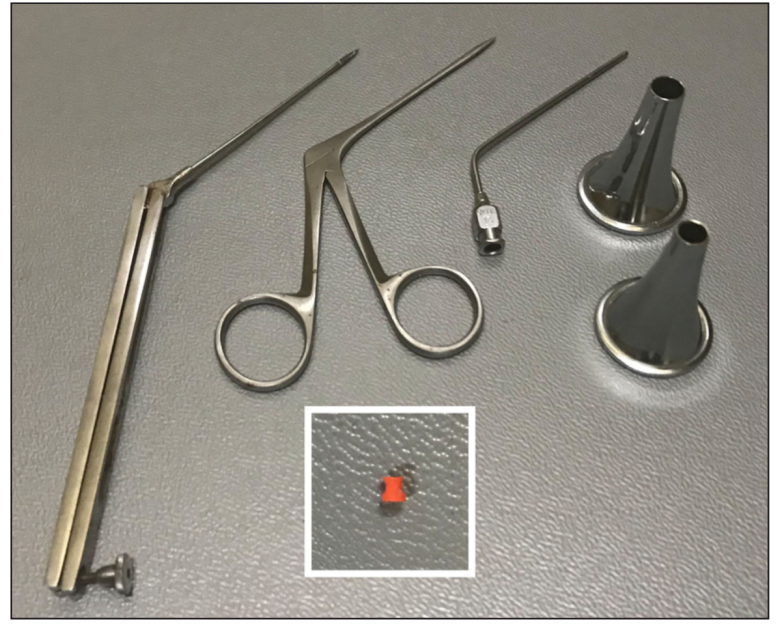

Figure 5. Instruments (from left to right): folding myringotomy knife, micro aural crocodile forceps, Rosen suction tip gauge 15, and Boucheron endaural speculae. Shepard grommet (inset)
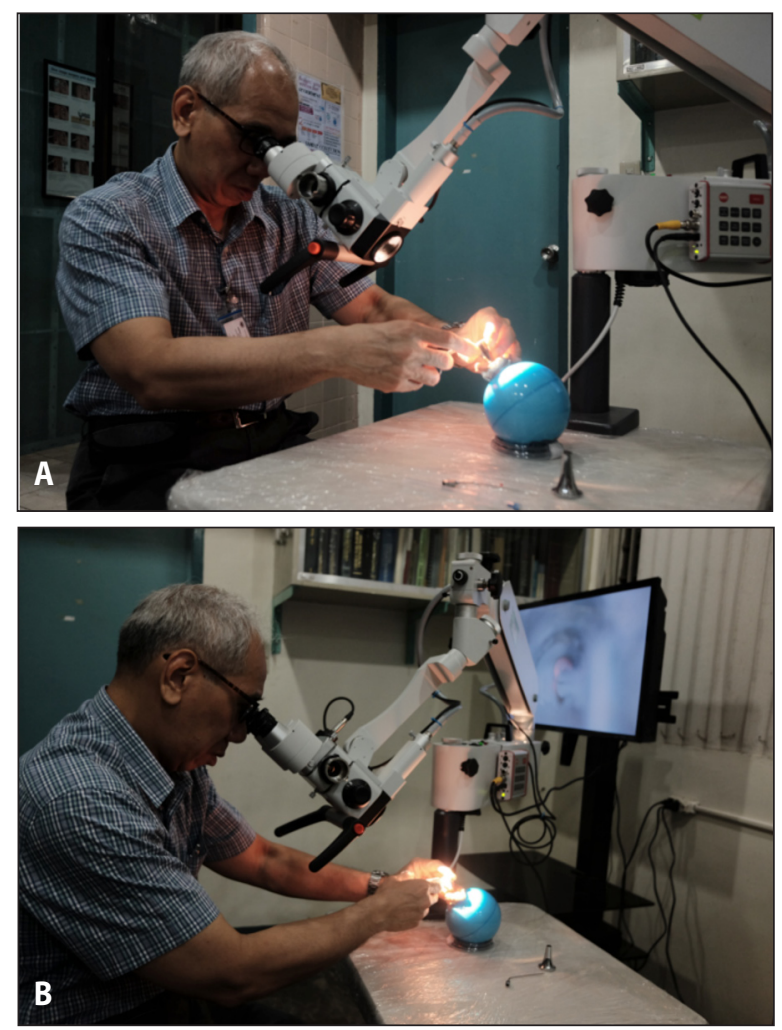

Figure 6. Actual set up of the simulation.

The data sheet and observation checklist of Volsky et al. were adapted for this study. ${ }^{2}$ Criteria for trial failure included: (1) dropping the ventilation tube in the middle ear space or (2) inability of tube to remain suspended within the myringotomy incision due to membrane damage. Criteria for error included all criteria for trial failure as well as: (1) injury to the external auditory canal (manifesting as a clunking sound signifying contact of the instrument and canal wall), (2) when the tip of an instrument grasping the tube was pushed entirely through the membrane, (3) when an instrument was dropped, (4) when the tube was dropped outside the ear, (5) incorrect site of incision, (6) when more than 2 attempts at performing the myringotomy incision was done, or (7) when there was damage to another part of the tympanic membrane, other than the incision site. An objective structured clinical examination (OSCE) checklist of these adverse events was used to evaluate a resident's performance. (Table 2) Each error made corresponded to a one-point deduction from a score of 7 . Trial failure resulted in a 50\% deduction in overall score. Scores from the 3 trials were then added to generate an OSCE score (perfect score of 21).

\section{Data Analysis}

Microsoft Excel 2011 version 14.7.3 (Microsoft, Redmond, WA, USA) was used to tabulate and process the data gathered. The T-test for independent samples and Fisher Exact Test were performed using Stata Statistical Software, Release 12 (StataCorp, LP, 2011, College Station, TX, USA).

\section{RESULTS}

\section{Qualitative Validation of Simulation Model by Experts}

Three actively practicing otologists participated in this study. The average duration in performing the trials for all consultants was 82 seconds (range 35 to 140 seconds).

There were 2 failures out of 9 total trials with a total of 6 errors committed. One consultant had a failed trial due to the tube being dropped into the middle ear while another was due to inability of the tube to maintain its position due to membrane damage. General comments regarding the ear model were that the artificial tympanic membrane was tougher than the natural tympanic membrane, the myringotomy knife was dull and the instruments provided during the procedure were not the usual instruments they would use. One of the consultants preferred to use a spinal needle instead of a myringotomy knife, and two preferred to use a curved micro ear needle for VT insertion rather than the micro crocodile forceps. However, all consultants were in agreement that the artificial tympanic membrane behaved realistically. All consultants were also in agreement that the setting (which includes the room, the microscope and the instruments) approximated actual clinical experience, and that the ear model would be a valuable learning tool for the residents.

\section{Qualitative Validation of Simulation Model by Trainees}

Fifteen (15) residents (from $1^{\text {st }}$ to $4^{\text {th }}$ year) participated in the trials. (Table 3) Ten of the 15 had not attended a temporal bone dissection course (junior residents), while 5 had already attended the course (senior residents). The average length of time needed for residents to complete the procedure was 87 seconds (range 20 seconds to almost 5 minutes). The average OSCE score for all residents was 17.17. 


\section{ORIGINAL ARTICLES}

Table 1. Evaluation of Simulation by Experts

\begin{tabular}{|l|l|l|l|l|l|}
\hline $\begin{array}{l}\text { The setting (room, instruments, microscope) } \\
\text { approximated the real thing }\end{array}$ & SA & A & N & D & SD \\
\hline $\begin{array}{l}\text { The anatomy of the model (pinna, EAC, TM) } \\
\text { approximated the real thing }\end{array}$ & & & & \\
\hline The artificial TM behaved realistically & & & & \\
\hline $\begin{array}{l}\text { I feel that this can be a valuable learning tool for } \\
\text { the residents }\end{array}$ & & & & & \\
\hline
\end{tabular}

SA-Strongly Agree; A-Agree; N-Neither Agree of Disagree; D-Disagree; SD-Strongly Disagree

Table 2. Objective Structured Clinical Examination (OSCE) Checklist for Trainees

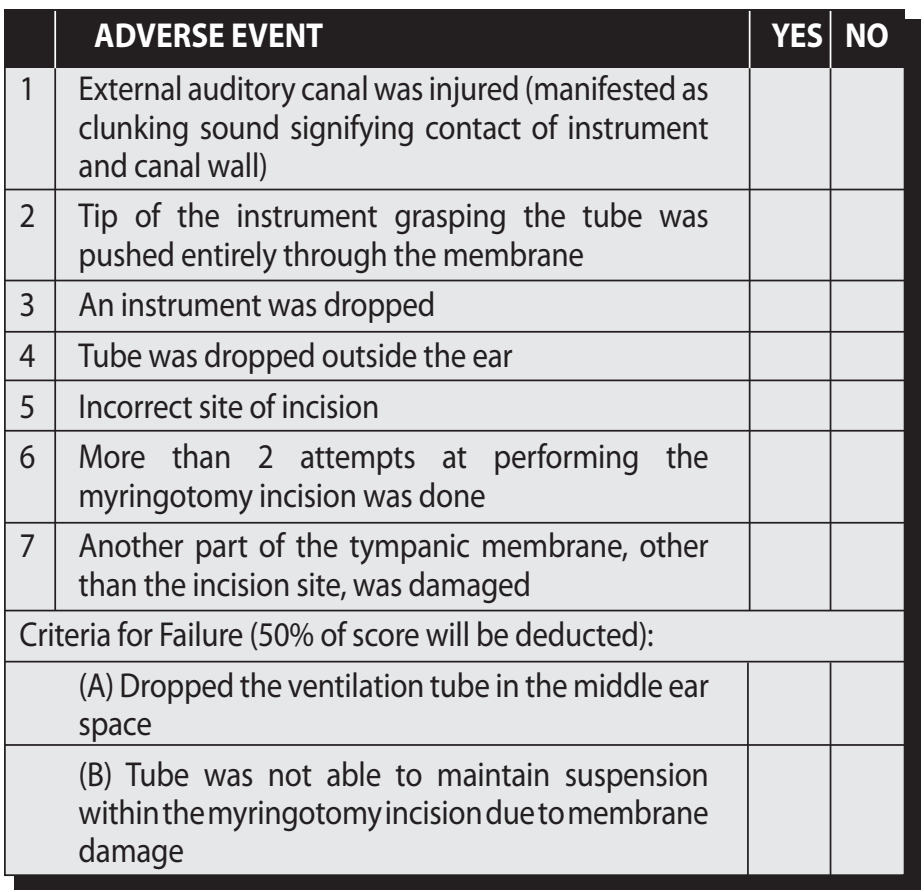

Table 3. Summary of Residents' Performance

\begin{tabular}{|l|r|r|r|r|}
\hline Number of Residents & $\begin{array}{c}\text { Junior } \\
\text { Residents }\end{array}$ & $\begin{array}{c}\text { Senior } \\
\text { Residents }\end{array}$ & Overall & $\begin{array}{c}\mathbf{P} \\
\text { value }\end{array}$ \\
\hline $\begin{array}{c}\text { Average time per trial } \\
\text { in seconds (mean } \pm \\
\text { standard deviation) }\end{array}$ & 10 & 5 & 15 & $.38^{\mathrm{c}}$ \\
\hline $\begin{array}{c}\text { OSCE Score, (mean } \pm \\
\text { standard deviation) }\end{array}$ & $16.6 \pm 2.11$ & $18.3 \pm 3.07$ & $17.17 \pm 2.50$ & $.60^{\mathrm{d}}$ \\
\hline $\begin{array}{c}\text { Percentage (\%) of residents } \\
\text { with OSCE Score }>75 \%\end{array}$ & 606 & $106.73 \pm 77.75$ & $87.36 \pm 52.14$ & $.227^{\mathrm{c}}$ \\
\hline
\end{tabular}

a Mean duration and standard deviation of trial in seconds. Trials resulting in failure were excluded since there is no recorded time.

${ }^{b} M e a n$ and standard deviation, with perfect score of 21

'T-test for independent samples, two-tailed, level of significance $=0.05$

${ }^{d}$ Fisher exact test, two-tailed, level of significance $=0.05$
Table 4. Percentage of Errors and Failures by Residents

\begin{tabular}{|c|c|c|c|c|}
\hline & $\begin{array}{c}\text { Junior } \\
\text { Residents }\end{array}$ & \begin{tabular}{|l} 
Senior \\
Residents
\end{tabular} & Overall & $\begin{array}{c}P \\
\text { value }\end{array}$ \\
\hline $\begin{array}{l}\text { Total number of possible } \\
\text { errors }^{\mathrm{a}}\end{array}$ & 210 & 105 & 315 & \\
\hline $\begin{array}{l}\text { Percentage }(\%) \text { of missed } \\
\text { steps or errors }\end{array}$ & 11.4 & 7.62 & 10.16 & $.33^{c}$ \\
\hline $\begin{array}{l}\text { 1) More than } 2 \text { attempts at } \\
\text { performing myringotomy }\end{array}$ & 3.8 & 1.90 & 3.2 & $.51^{c}$ \\
\hline $\begin{array}{l}\text { 2) Tube pushed into middle } \\
\text { ear }\end{array}$ & 3.33 & $<1$ & 2.5 & $.28^{c}$ \\
\hline $\begin{array}{l}\text { 3) Injury to parts of TM other } \\
\text { than site of incision }\end{array}$ & 2.38 & 1.90 & 2.2 & $1.0^{c}$ \\
\hline 4) Injury to the EAC & $<1$ & 1.90 & 1.27 & $.60^{c}$ \\
\hline 5) Incorrect site of incision & $<1$ & $<1$ & $<1$ & $1.0^{c}$ \\
\hline $\begin{array}{l}\text { 6) Tube dropped outside the } \\
\text { ear }\end{array}$ & $<1$ & 0 & $<1$ & $1.0^{c}$ \\
\hline 7) Instrument dropped & 0 & 0 & 0 & $1.0^{c}$ \\
\hline Total number of trials ${ }^{b}$ & 30 & 15 & 45 & \\
\hline $\begin{array}{l}\text { Percentage (\%) of failed } \\
\text { trials }\end{array}$ & 20 & 13.3 & 17.78 & $.70^{c}$ \\
\hline $\begin{array}{l}\text { (A) tube was dropped in the } \\
\text { middle ear }\end{array}$ & 10 & 13.3 & 11.11 & $1.0^{c}$ \\
\hline $\begin{array}{l}\text { (B) tube was unable to } \\
\text { maintain its position due } \\
\text { to membrane damage }\end{array}$ & 10 & 0 & 6.67 & $.54^{c}$ \\
\hline
\end{tabular}

a Obtained as a product of the number of residents, types of adverse events, and number of trials per resident

${ }^{b}$ Obtained as a product of the number of residents and number of trials per resident

cFisher exact test, two-tailed, level of significance $=0.05$

Table 5. Production Cost of Simulation Model

\begin{tabular}{|c|c|c|}
\hline ITEM & COST (PhP) & COST (USD) \\
\hline Silicone sealant with gun (1 tube)* & 400.00 & 7.70 \\
\hline Acrylic paint (1 bottle)* & 100.00 & 1.90 \\
\hline Alginate cast (1pack)* & 300.00 & 5.80 \\
\hline Labor and materials, metal tube & $2,000.00$ & 38.50 \\
\hline Rubber ball & 100.00 & 1.90 \\
\hline Plaster of Paris (1 pack)* & 100.00 & 1.90 \\
\hline Endotracheal tube $\times 2$ & 80.00 & 1.5 \\
\hline TOTAL & $\mathrm{PhP} 3,080.00$ & USD 59.00 \\
\hline
\end{tabular}

*Can be used to make multiple models 


\section{ORIGINAL ARTICLES}

There were 8 failures (17.78\%) out of 45 total trials with a total of 32 errors committed but none of the residents experienced more than 1 failure each. The most common reasons for failure and errors are shown in Table 4. Most residents had difficulty estimating the size of the myringotomy incision necessary to make the ventilation tube fit. As a result, they would either widen the initial myringotomy incision (some required more than 2 attempts-most common error) or force the tube to fit the original incision which would result in the tube being pushed into the middle ear space due to excessive force $\left(2^{\text {nd }}\right.$ most common error).

Senior residents performed better generally in all parameters; they were less likely to commit errors and their trials were less likely to result in failures but none of these parameters were statistically significant (Fisher exact test, 2 tailed $p$-value of .33 for errors, and .70 for failures, level of significance $=0.05$ ). Senior residents had a higher average OSCE score of 18.3 compared to the junior residents with an OSCE score of 16.6 but this was not statistically significant ( 2 tailed t-value, significance level $0.05=-1.27, p=.227$ ). The passing rate for performing the procedure was $75 \%$ or an OSCE score of $15.75 / 21$. More senior residents achieved the passing score than did junior residents but this was not statistically significant (Fisher exact test, 2 tailed $p$-value $=$ .6004 , level of significance $=0.05$ ).

\section{DISCUSSION}

We developed a simulation model and demonstrated that it can be used to teach, evaluate and improve the MVTI skills of otorhinolaryngology residents.

Numerous simulation platforms for MVTI have been made using various materials with different levels of replicability, validity and cost approximations. Mahalingam et al. performed a 2015 literature review of 11 simulation models, of which only 5 underwent validity assessment, 2 relied on virtual reality and only 5 were deemed feasible to replicate. 'The diameter of the tympanic membrane in these models ranged from 6 to $10 \mathrm{~mm}$ while the length of the external auditory canal ranged from 2.1 to $4.0 \mathrm{~cm}$. The various materials used for the tympanic membrane included plastic, adhesive tape, latex, vinyl, cellophane and nitrile. Most of the studies reviewed did not include the approximate cost of producing the simulation but among those that did, the highest cost was at $£ 2.10$ (approximately USD 2.79 or PhP 131.00 in 2015, and USD 2.79 or PhP 149.00 in 2018). The five feasible models were replicated and assessed by experts. The study concluded that none of these models achieved face or global content validity. ${ }^{\prime}$

In 2008, Uy and Martinez ${ }^{3}$ fashioned a do-it-yourself myringotomy model from recycled plastic egg crate, 3-cc plastic syringe, medical tape and modeling clay that then cost approximately PhP 100 (approximately USD 1.90 in 2008 and approximately USD 2.50 or PhP 130 in 2018). However, we believe the materials they used are easily prone to wear and tear and would have to be constantly replaced and refashioned. In 2015, Amable and Sia-Vargas fabricated an instrument that can perform both myringotomy and ventilation tube insertion using chicken egg membrane as a model for the tympanic membrane. ${ }^{4}$ However, the model used in their study does not mimic the EAC anatomy. In addition, using chicken egg membrane for educational purposes might be impractical as it is too soft and fragile making it difficult to handle compared to the tympanic membrane.

The simulation platform developed may not be as inexpensive as previous models (Table 5) but the present authors believe it to be sturdier and more realistic. The pinna, bony and cartilaginous portions of the EAC, malleus and TM were simulated and an adjustable mount that allowed movement and manipulation of the model was created much like moving a patient's head during an actual procedure. The simulation was also versatile in allowing upright positioning to mimic a patient undergoing MVTI in a sitting position. Another advantage was its reusability - the procedure can be performed repeatedly on the same model and only the artificial tympanic membrane needs to be replaced. Hence, although the initial cost may be relatively high, it may be more cost-effective in the long term since its reusability will entail a cost of less than PhP 5 (USD 0.09) per replacement of the simulated tympanic membrane.

In clinical practice, the duration of the procedure performed on an actual patient ranges from 2 to 5 minutes under local anesthesia. The resident's performances during the timed trials appeared at par with the consultant's performances in terms of duration. However, this simulation experience was valuable for the residents as it allowed them to gain familiarity and dexterity in performing this basic procedure (experiential learning in knowing the steps, determining how much force was needed to place the ventilation tube without damaging the tympanic membrane, and how large the incision had to be for the tube to fit). Simulation of MVTI may lessen the chance of dropping the ventilation tube into the middle ear, which may complicate and require middle ear exploration. Two residents committed the error of placing the incision site too low and too close to the edge where the annulus should be although it is admittedly a limitation of the model that the annulus was not simulated.

Other common errors were injury to the tympanic membrane and external auditory canal (EAC), which were mostly a result of clumsy handling of instruments. Those who injured the tympanic membrane often inserted the micro crocodile forceps throughout and beyond the entire length of the ventilation tube such that the tip of the forceps would jut out and hit the tympanic membrane resulting in puncture in contrast to grasping the tube using just its outer lip. Errors were committed and as part of the learning process the investigators pointed out the mistakes made so that they could be avoided in the future.

Evaluation of the simulation was generally positive. When asked to compare the simulation model to actual surgery, one senior resident 
mentioned that it would have been a nice learning opportunity to do the procedure on a simulator prior to performing it on an actual patient. However, similar to the comments of some consultants, he also found the artificial tympanic membrane tougher to cut than an actual membrane. Perhaps the toughness of the tympanic membrane can be modified in future trials using materials from balloons, latex gloves or condoms to simulate varied tensile strength. However, it may not so much be the toughness of the membrane but the sharpness of the instruments that allow a controlled incision on the membranes. Perhaps a single use spinal needle or myringotomy blade used to incise the tympanic membrane may be better than a reusable myringotomy knife. Moreover, the role of a tympanostomy tube applicator that also performs the myringotomy may be worth considering. ${ }^{5}$ Such options may be made available during simulation allowing operator preference to determine the materials to be used in actual practice and future trials may compare them to each other.

Although not statistically significant, senior residents performed better in general than their junior counterparts having committed less errors, less failures and achieving better overall OSCE scores. Perhaps familiarity with the use of an operating microscope might have contributed to this trend. Microscope handling is an important aspect to consider in performing MVTI. More junior residents were observed to have had greater difficulty in manipulating the microscope (e.g. adjusting focus and inter pupillary distance), presumably due to unfamiliarity and lack of experience. Implementation of the simulation model may be incorporated in otology courses conducted yearly by the department since microscope handling is introduced during this time.

Nine of the residents were surprised at how difficult it was to perform MVTI initially because the video they were asked to watch made it look easy. Each resident performed a limited number of trials and it may be inappropriate to conclude that a resident who performed worse on the third compared to the first trial performed poorly. At the same time, shorter duration and fewer errors committed for each succeeding trial should not be associated with improvement. More trials should be performed to determine consistency in performance for each resident. Causes of failure and complications are best simulated so as to prevent these from happening on an actual patient.

One limitation of the study was the restriction in the instruments as well as the technique that was made available to perform the MVTI. Residents were taught only one technique using a prescribed set of instruments. However, as mentioned previously, an expanded array of instruments may be made available. Residents may be allowed even encouraged, to explore various techniques using the simulation (e.g. the use of a spinal needle Rosen needle in lieu of a reusable myringotomy knife and micro aural crocodile forceps), without harm to a patient.

Another limitation of the study is the inability to determine the point in the evaluation process when the simulation would have any true impact in a resident's performance on actual patients. Residents who show adequate dexterity and consistency during simulation (i.e., obtaining an OSCE score $>75 \%$ ) can eventually be allowed to perform the procedure on patients, and provide feedback regarding the usefulness of the simulation. True impact may be prospectively assessed in subsequent patient encounters.

Modifications on the current simulator may also be made to expand its applications to potentially include endoscopic myringotomy or inlay graft tympanoplasty. It is important to note that the study involved simulation of a right adult ear and performing this procedure on the left ear or on the pediatric/infant population might be a different experience. A left ear model and a pediatric model will be fabricated in the future to address the limitations of this present model. The model can also be modified to allow interchanging tubes of different diameters to provide users with varying levels of difficulty.

This simulation platform may be a valuable tool to use in educating and developing skills and proper technique of residents-in training in otorhinolaryngology. It is readily reproducible, affordable, realistic, sturdy and versatile in its applications and it promotes patient safety. Causes of failure and complications are best simulated to prevent these from happening on an actual patient. Residents who show adequate dexterity and consistency during simulation should eventually be allowed to perform the procedure on patients and provide feedback regarding the usefulness of the simulation.

\section{ACKNOWLEDGEMENTS}

We would like to express our gratitude to our prosthesis fellows Dr. Anna Claudine Lahoz, Dr. Pamela Nicole Ladrido and Dr. Carlo Victorio Garcia for their assistance in the creation of the ear model.

\section{REFERENCES}

1. Mahalingam S, Awad Z, Tolley NS, Khemani S. Ventilation tube insertion simulation: A literature review and validity assessment of five training models. Clin Otolaryngol. 2016 Aug. 41(4): 321-6. DOI: 10.1111/coa.12543. PMID: 26385050.

2. Volsky PG, Hughley BB, Peirce SM, Kesser BW. Construct validity of a simulator for myringotomy with ventilation tube insertion. Otolaryngol Head Neck Surg. 2009 Nov; 141(5): 603-608 e1. DOI: 10.1016/j.otohns.2009.07.015. PMID: 19861198.

3. Uy MJS, Martinez NV. Model myringotomy practice set: A do-it-yourself and inexpensive alternative. Philipp J Otolaryngol Head Neck Surg. 2008 Jan-Jun; 23(1): 31-34.

4. Amable JP, Sia-Vargas LL. A myringotomy and ventilating tube applicator: New look at a fivecentury-old procedure. Philipp J Otolaryngol Head Neck Surg. 2015 Jul-Dec; 30(2): 50-55.

5. Aguila KP. Self-retaining harpoon tympanostomy tube with applicator. Philipp J Otolaryngol Head Neck Surg. 2007 July-Dec; 22 (1,2): 27-30.

6. Fernando AF, Calavera KZ. Endoscopic myringotomy and ventilation tube placement: $A$ valuable otolaryngologic procedure under topical anesthesia. Philipp J Otolaryngol Head Neck Surg 2012; 27 (1): 41-43.

7. De Leon RO, Amable JP. Optical myringotomy knife. Philipp J Otolaryngol Head Neck Surg 2017; 32 (1): 51-54.

8. YouTube. Insertion of ventilation tube for ear infections [video]. Boston (MA). Massachusetts Eye and Ear Infirmary, Harvard Medical School; 2007. [Accessed 2018 April 15]. Available from https://youtu.be/66rQwocHahl.

9. YouTube. Endoscopic ventilation tube insertion [video]. Brazil. [Accessed 2018 April 15] Availalble from https://youtu.be/cOqY6s5w9Gs. 